\title{
SEIS MESES DE COVID-19 EN CHILE: EXPLORANDO EL ROL DEL TRÁFICO AÉREO Y EL MERCADO DEL TRABAJO EN EL BALANCE DE CONTAGIOS Y FALLECIDOS
}

\section{SIX MONTHS OF COVID-19 IN CHILE: EXPLORING THE ROLE OF AIR TRAFFIC AND THE LABOR MARKET IN THE BALANCE OF INFECTIONS AND DEATHS}

Francisco Maturana*

Víctor Cobs-Muñoz * *

Catalina Pérez ${ }^{* * *}$

RESUMEN: La pandemia mundial del Covid-19 se ha propagado a tal rapidez que llega a Chile en menos de cuatro meses desde su primer caso registrado en 2019. Este importante evento, en el contexto epidemiológico, del país gatilla medidas preventivas y reactivas desde el ejecutivo y la sociedad en general en dirección a reducir la velocidad de contagio y la presión hacia la red de atención en salud. Una de dichas medidas responde al cierre de fronteras, afectando el flujo aéreo, tanto internacional como nacional. Este artículo explora la relación entre los flujos aéreos comerciales y la rama de actividad económica con la cantidad de contagiados y fallecidos por Covid-19 en las regiones chilenas. Para tal efecto, mediante gráficos combinados, correlaciones y regresiones, apreciamos que existió una drástica disminución de los flujos aéreos comerciales a partir de la tercera semana desde declarada la pandemia, no obstante, algunas regiones retoman los flujos de manera posterior. Se observa una relación entre flujos aéreos, actividades productivas mineras en el norte del país y nivel de contagio, además de ser esta macrozona la que ha presentado elevados niveles de Covid-19. Además, apreciamos que existe una alta y significativa correlación entre cantidad de población y contagios-fallecidos, dejando en evidencia que existe un proceso de difusión espacial de la pandemia mediante una estructura jerárquica enmarcada por la distribución de la población chilena. Si bien los resultados acá planteados son exploratorios y restan abiertos a la discusión, contribuyen a dejar en evidencia los procesos ya indicados y vividos en los primeros meses de la pandemia.

Palabras clave: Coronavirus, vuelos comerciales, transporte aéreo, contagio, pandemia.

Recibido: 13.11.20 Aceptado: 11.12.20

\footnotetext{
* Instituto de Ciencias de la Tierra, Universidad Austral de Chile, francisco.maturana@uach.cl ttps://orcid.org/0000-0003-3963-5807

** School of Spatial Planning, TU Dortmund, victor.cobs@tu-dortmund.de https:/ / orcid.org/0000-0002-9965-9889

***Departamento de Geografía, Universidad Alberto Hurtado ca.pereznavarrete@gmail.com
} 
ABSTRACT: The global pandemic of COVID-19 has spread so rapidly that it has reached Chile in less than four months since its first recorded case in 2019. This important event in the epidemiological context of the country triggers preventive and reactive measures from the executive and the society in general in order to reduce the pace of contagion and the pressure on the healthcare network. One of these measures is the closing of borders, affecting both, international and domestic flights. This article explores the relationship between commercial air traffic and the branch of economic activity with the number of COVID-19 infections and deaths in Chilean regions. For this purpose, by means of combined graphs, correlations, and regressions, we show that there was a drastic decrease in commercial flights from the third week after the pandemic was declared; however, some regions resumed flights later on. A relationship is observed between air traffic, mining production activities in northern Chile, and the level of infection, in addition to the fact that this macro-zone has presented high levels of Covid-19. Moreover, we found that there is a high and significant correlation between the population size and infection-deaths, showing a process of spatial diffusion of the pandemic through a hierarchical structure framed by the distribution of the Chilean population. Although the results presented here are exploratory and remain open to discussion, they contribute to demonstrate the processes already indicated and experienced in the first months of the pandemic.

Keywords: Coronavirus, commercial flights, air transport, contagion, pandemic.

\section{INTRODUCCIÓN}

A lo largo de la historia humana la población y continentes han estado conectados entre sí dada una amplia gama de motivos, como comercio, turismo y trabajo, entre otras (Barjamovic, 2018; Larsen, 2015). Tal conexión ha producido lo que en geografía se ha denominado corrientemente como el proceso de difusión espacial, que se desencadena producto de la interacción y conexión entre personas, la cual se puede comprender como un fenómeno de propagación en el tiempo y espacio de una cosa específica, objetivo, institución, idea, etc., por medio de individuos, grupos o cualquier otra entidad potencial de acoger localmente lo anterior (Pumain y Saint-Julien, 200 1). Por lo tanto, a medida que se incrementan las conexiones entre territorio debido a tales relaciones de intercambio, también aumenta el contacto entre habitantes $y$, por ende, tal proceso de difusión espacial, trayendo consigo no sólo la propagación de ideas, tecnología y otros, sino que también la propagación de virus en distintos periodos de la historia humana (Congdon, 2016; Saccomandi, 1997).

Las propagaciones de virus en un contexto geográfico siguen la lógica de la existencia de un lugar (territorio) emisor $y$, en este caso, una enfermedad susceptible a ser propagada en el espacio por medio de vectores, en el caso actual del SARS-CoV-2, los seres humanos (Cuadros et al., 2020). Por tanto, este lugar emisor tendrá características particulares y según estas y mediante canales y duración específica podrá propagar hacia otros territorios que estarán compuesto por adoptantes 
potenciales y cuyas características propias posibilitan tal proceso (Brown y Cox, 1971), por tanto, entregando una diferenciación en los lugares en términos de adopción (CDC, 2020)

Así, los medios de dichas propagaciones han estado constituidos de manera variable. Según Karlen (1995), en tiempos antiguos, las enfermedades se propagaban de manera veloz entre la población por medio de caminatas, y estas se fueron incrementando, a medida que se sumaban nuevos medios de transportes, como el caballo, carretas o barcos. En tal sentido, las nuevas tecnologías en transporte y telecomunicaciones han propiciado que a nivel global las sociedades se encuentren cada vez más interconectadas, por medios de transporte terrestres (automóviles y ferrocarriles) y aéreos (aviones) y marítimos (barcos y cruceros) (Ducruet, 2013), incrementando la velocidad de propagación y contagio de los virus. Un ejemplo específico se puede observar en la difusión de virus a través de los exploradores y colonizadores que infectaron poblaciones indígenas, las cuales no contaban con inmunidad a los patógenos del 'Viejo Mundo' (Pringle, $2015)$. En efecto, en los últimos cinco siglos las enfermedades de carácter pandémicas han aumentado considerablemente (Karlen, 1995), generando altos niveles de morbilidad y mortalidad, como ocurrió con la peste negra, cólera $\circ \mathrm{VIH}$ (Duplaix, 1998; Jonassen, 1997; Rogers, 19201, siendo, en la gran mayoría de los casos mencionados, el principal factor de contagio el ser humano, al ser este un ser sociable y móvil que le otorga características esenciales como vector de trasmisión (Huang, et al., 2020; Jia et al., 2020).

Uno de los medios que ha posibilitado una virus han sido los vuelos comerciales (Colizza, et al., 2006; Lau, et al., 2020), tales flujos facilitan pasar rápidamente de una escala nacional a una internacional en la propagación del virus, generando una "pandemia mundial", esto se observa al considerar la cantidad total de 4.377.670.000 pasajeros transportados por aire en 2018 (International Air Transport Association, 20191.

Desde marzo 2020, el mundo se encuentra en una pandemia global producto del Covid-19 causada por el SARS-CoV-2 lacrónimo en inglés para Severe Acute Respiratory Syndrome Coronavirus 21 Organización Mundial de la Salud, 2020al, un virus que por el momento se cree tener un origen zoonótico, reportado por primera vez el 31 de diciembre, 2019 en Wuhan, China. Desde ese entonces los casos registrados experimentaron un súbito incremento, evidenciando la expansión del virus a través de diferentes regiones y países. Por consiguiente, en enero 2020, el Director-General de la lo mismo que en la Organización Mundial de la Salud (OMS), declaró el brote de Covid-19 como una emergencia sanitaria de carácter público y de importancia global.

El Covid-19 tardó 3 meses en llegar a Chile, lo cual ocurre el 2 de marzo del 2020, según el Ministerio de Salud (MINSAL, 2020a), por medio de un pasajero que arriba al país a partir de un vuelo proveniente del sudeste asiático. El día 3 de marzo del 2020, se detectó un segundo caso, el cual correspondía a una pasajera que, llegada desde Europa, presentaba los síntomas, ambos casos en la región del Maule (Figura 1).

Los siguientes casos registrados a nivel país consistieron en casos importados, en donde los pasajeros que llegaron desde el 27 de 
enero del 2020 al 29 de febrero del 2020 provenían de países como: España, Tailandia, Singapur, Malasia, Italia, Maldivas, Indonesia, Francia y Reino unido (Ministerio de Salud, 2020b), los cuales no presentaban síntomas a la hora de viajar (dado periodo de incubación), permitiendo que se desencadenara un contagio producto de portadores asintomáticos.

En concordancia con la región latinoamericana y el mundo, el 16 de marzo el presidente Sebastián Piñera informó que las fronteras terrestres, marítimas y aéreas serían cerradas el 18 de marzo para personas extranjeras, 16 días después del primer caso. La expansión del virus dentro del país fue rápida. En sólo 14 días del primer caso reportado a nivel nacional, Chile pasó de la fase 1 a la fase 4 (MINSAL, 2020), lo cual significó que las personas que presentaron síntomas ya no eran exclusivamente provenientes de otros países con casos reportados, sino que también de una transmisión humano-humano verificada al interior del país. En otras palabras, existía una circulación viral y expansión comunitaria del virus que desataba la enfermedad con una trazabilidad completamente perdida.

En cuanto a los vuelos internacionales, estos comenzaron a disminuir sus flujos a medida que otros países decidieron cerrar sus fronteras. Además, el periodo de vacaciones en Chile (enero y febrero) finalizaba y, por tanto, las personas que se encontraban en el extranjero por vacaciones en gran medida ya habían regresado. En términos de los flujos nacionales, estos se seguían realizando a lo largo de todo el territorio y su descenso no fue hasta la tercera y cuarta semana una vez llegado el virus. De manera general, según los datos de la Junta Aeronáutica Civil (UAC) (2020), en el mes de marzo una disminución del 20\% en la cantidad de pasajeros transportados dentro del territorio nacional en comparación con el mes de febrero, lo cual era esperable considerando el periodo de vacaciones y la alta movilidad en tal mes del año. Sin embargo, la disminución más drástica se presentó en el mes de abril, la cual consistió en una baja de un 51\% menos de pasajeros transportados respecto al mes de marzo, lo cual dejaba en evidencia el impacto del virus en los vuelos comerciales.

No obstante, tal notable caída en los números, esto no significó una paralización o ausencia de estos, los cuales se siguieron desarrollando particularmente hacia las regiones que se vinculan a actividades de carácter mineras o salmoneras, es decir, actividades primarias vitales para la economía del país. Además, las condiciones geográficas de extensión del territorio nacional, de prácticamente 4.000 kilómetros de largo y cuyas características en términos de conectividad particular al contar con una baja red ferroviaria, hacían prácticamente inviable la ausencia de vuelos hacia las ciudades localizadas en los extremos de la nación.

Es en tal dirección, que este artículo, buscó explorar el comportamiento de la propagación del COVID-19 en las regiones de Chile a 6 meses de su Ilegada, indagando si tal proceso se podría asociar al comportamiento de los flujos aéreos comerciales y mercado del trabajo. Se expresa que las regiones del norte del país, vinculadas a la actividad minera, han presentado proporcionalmente mayores casos de COVID-19 y los vuelos aéreos comerciales se han seguido desarrollando pese a una disminución inicial. Además, si bien existe esta particularidad en el norte del país, la Región Metropolitana, donde se localiza la capital y mayor población del 
territorio nacional, es la unidad espacial Pesca; Minas; Industria; Electricique ostenta mayores contagios y dad-Agua-Gas; Construcción; Comercio; defunciones. En tal sentido, la propagación Hotelería-Restaurante; Transporte; Finandel virus ha seguido un patrón en función de cieras; Inmobiliaria y empresas; Adminisla cantidad de población, aunque con tración Pública; Enseñanza; Salud; Servicio; particularidades de ciertos focos emisores Hogar Privado. Con tal base de datos se (territorio particular).

El aporte de este trabajo en el contexto geográfico, se enmarca en considerar y revelar a la escala regional como una unidad espacial fundamental para este análisis, considerando la existencia de un solo aeropuerto o aeródromo para cada región, localizado en su capital, y teniendo presente que esta se podría transformar en la puerta de entrada para la propagación del virus a otras urbes de la región.

\section{MATERIALES Y MÉTODOS}

Para llevar a cabo este artículo se consideraron los datos publicados por el Ministerio de la Ciencia y Tecnología en coordinación con el Ministerio de Salud chileno (MINSAL) referente a número de contagiados y número de fallecidos por Covid-19. Además, desde la Junta Aeronáutica Civil, se procesó la cantidad de personas que volaron de una región a otra. Los anteriores se complementaron con la información del censo de población del año 2017, donde se extrajo la población total por región y cantidad de trabajadores en cada área de actividad económica según la Clasificación industrial internacional uniforme (CIIU) de las Naciones Unidas (ONU, 2008). Tal clasificación está compuesta por diferentes ramas agrupadas en 15: Agricultura y aplicó el coeficiente de especialización, donde a mayor valor existe más concentración del empleo en una(s) de las actividades económicas. Se consideró este índice por su tradición de aplicación por parte de la Comisión Económica para América Latina y el Caribe (CEPAL) en el contexto de los territorios de América Latina para espacios regionales (Soza-Amigo, et al., 20181.

La escala de trabajo fue a nivel regional, puesto que solamente una ciudad en cada región (y no en todas) poseen un aeropuerto, en algunos casos algunas se califican como aeródromo, por su mejor tamaño. Por lo tanto, trabajar a otra escala no se consideró pertinente, puesto que el sentido de los flujos aéreos y los contagios vinculados a ellos se perdía completamente. En tal sentido, la ciudad donde se localiza el aeropuerto de la región es la puerta de entrada para tal espacio en términos de flujos.

Además, se refuerza la selección de tal escala al observar el porcentaje de población contagiada en la capital (donde se localizan tales aeropuertos) respecto del total regional en cada uno de estos espacios. Como se aprecia en la Tabla 1, tal porcentaje es bastante elevado para la gran mayoría de las comunas que ostentan el rango de capital regional, seleccionadas en este estudio. 


\begin{tabular}{|l|l|}
\hline Capital regional & Porcentaje de contagiados respecto al total de la región \\
\hline Arica y Parinacota & 100 \\
\hline Antofagasta & 53,5 (considerar que Calama comuna minera concentra el 39\%) \\
\hline Copiapó & 69 \\
\hline Coquimbo-La Serena & 71,8 \\
\hline Temuco & 27,5 \\
\hline Puerto Montt & 52,3 \\
\hline Coyhaique & 48,3 \\
\hline Punta Arenas & 96,6 \\
\hline
\end{tabular}

Tabla 1. Porcentaje de contagiados en la capital regional respecto al total regional (al 31-08-2020) Fuente: Elaboración propia a partir de MINSAL, 2020 y Junta de Aeronáutica Civil, 2020.

Cabe destacar que, en las cuatro primeras regiones del país de norte a sur, la cantidad de población total que concentra cada capital regional respecto a su total de la región supera el $80 \%$ (en la primera bordeando el 100\%), misma situación en las 2 regiones más australes del país, incluso en las áreas centrales los porcentajes son cercanos al 50\%, exceptuando por la región Metropolitana que nuevamente bordea sobre el 90\% (INE, 2017). Por lo tanto, al estar considerando las capitales regionales, se está abarcando la unidad espacial que contiene la mayor parte de población total de cada espacio regional y bajo ese precepto es que también se estima la justificación de haber seleccionado tal escala de análisis.

La cantidad de pasajeros transportados por flujos aéreos son recopilados por la Junta Aeronáutica Civil a partir de la información que se obtiene en cada uno de los vuelos comerciales realizados en el territorio nacional. Por tanto, corresponden a la cantidad total de pasajeros acumulados en el periodo a considerar. Por la naturaleza del dato, se consideraron las llegadas a cada espacio regional.

Respecto a los contagiados, se consideraron los casos positivos, tanto sintomáticos como asintomáticos, informados por la red de laboratorios de diagnóstico de exámenes
PCR que son a su vez informados y sistematizados por el MINSAL, que posteriormente pone a disposición tal información. En el caso de los fallecidos, estos son informados desde el Registro Civil chileno al MNNSAL que sistematiza tal información.

Con las distintas fuentes señaladas, se elaboraron 4 bases de datos por región, de los contagiados, fallecidos, el total de llegadas de pasajeros por flujos aéreos y finalmente el total de trabajadores por área de actividad económica. Para su presentación y análisis se debió efectuar un tratamiento que permitiera temporalmente su comparación en cuanto al caso de contagiados-fallecidos con los pasajeros aéreos, lo cual se detalla a continuación.

Según la Organización Mundial de la Salud (2020b) el tiempo que transcurre entre la exposición al Covid-19 y el desarrollo de los síntomas varían entre 1 y 14 días, aunque suelen aparecer entre el día 5 y 6 . Además, es necesario considerar el tiempo transcurrido entre el examen PCR y la notificación. Dado lo anterior, se estimó pertinente comparar los datos con 15 días desfasados. Es decir, la semana de vuelos 1 y 2, se comparó con la semana de contagios y fallecidos 3 y 4 y así respectivamente. Se seleccionaron 13 periodos de análisis en quincena (Tabla 2), según posibilidad de armonizar las bases de datos. 


\begin{tabular}{|c|c|c|c|}
\hline Fecha & Semana & Vuelos & Contagios/fallecidos \\
\hline 02/Marzo - 15/Marzo & 1 y 2 & $x$ & \\
\hline 16/Marzo - 29/Marzo & 3 y 4 & $x$ & $x$ \\
\hline 30/Marzo - 12/Abril & 5 y 6 & $x$ & $x$ \\
\hline $13 /$ Abril - 26/Abril & 7 y 8 & $x$ & $x$ \\
\hline 27/Abril - 10/Mayo & 9 y 10 & $x$ & $x$ \\
\hline $11 /$ Mayo - 24/Mayo & 11 y 12 & $x$ & $x$ \\
\hline 25/Mayo - 07/Junio & 13 y 14 & $x$ & $x$ \\
\hline 08/Junio - 21 /Junio & 15 y 16 & $x$ & $x$ \\
\hline 22/Junio - 05/Julio & 17 y 18 & $x$ & $x$ \\
\hline 06/Julio - 19/Julio & 19 y 20 & $x$ & $x$ \\
\hline 20/Julio - 02/Agosto & 21 y 22 & $x$ & $x$ \\
\hline 03/Agosto - 16/Agosto & 23 y 24 & $x$ & $x$ \\
\hline 17/Agosto - 30/Agosto & 25 y 26 & & $x$ \\
\hline
\end{tabular}

Tabla 2. Periodos de análisis Fuente: elaboración propia.

Así, se elaboran tres Figuras. La primera se compone de 3 gráficos de doble eje len escala logl, en los cuales se compara la cantidad de contagios y total de llegadas de pasajeros aéreos por periodo para cada una de las regiones de Chile. Estas se agrupan en zona norte, centro y sur para una mejor lectura. La segunda expresa el área de especialización de las regiones a partir de las actividades económicas de trabajo de los habitantes y la tasa de incidencia de contagios por región, esta última calculada a partir de la relación entre contagiados y total de población del espacio regional. Finalmente se sintetizan 5 correlaciones y regresiones simples en una Figura. La Población de cada región con: contagiados y fallecidos. Población con total de llegadas de pasajeros y finalmente contagios y fallecidos con el total de llegadas de pasajeros. Cabe señalar que los tratamientos de las bases de datos se realizan en el programa libre y gratuito $R$, mismos las gráficas que posteriormente fueron retocadas con el programa libre y gratuito Inkscape.

Cabe señalar que Chile está compuesto por 16 regiones con una desigual concentración de la población (Figura 1) y es en la Región Metropolitana es donde se localiza la capital del país (Santiago), la cual concentra aproximadamente el 37\% de la población total nacional (INE, 2017).

\section{RESULTADOS Y DISCUSIÓN}

En la Figura 1 se aprecia los 3 gráficos de doble eje ya indicados, no se incluyen las regiones de O'Higgins, Maule y Ñuble (color blanco en la Figura 1), puesto que no cuentan con vuelos comerciales. A modo general, se aprecia la existencia de una caída en los vuelos comerciales en las primeras 3 semanas desde el comienzo de la pandemia, para después estabilizarse o 
incluso en algunas regiones volver a aumentar. Pese a tal caída, los contagios se incrementan en gran parte de las regiones, por lo tanto, se constata: 1. La pandemia ha tenido un efecto en los vuelos comerciales domésticos, pero no ha suprimido la actividad. 2 En esta primera gráfica y a modo general no es posible observar un patrón que permita asociar claramente los vuelos y contagios en todas las regiones.

De manera particular, en la Zona Norte los flujos aéreos disminuyen, pero los contagios de la mayoría de las regiones aumentan en el periodo, específicamente desde el quinto. Esto es apreciable para Arica y Parinacota, Tarapacá y Antofagasta. En esta última región la curva de flujos aéreos disminuye en el periodo 3 para luego mantener un comportamiento casi constante. El punto más alto de contagios en la región se da en el octavo periodo con 3.658 contagiados, no existiendo un aumento en el arribo de pasajeros.

En la región de Atacama los flujos aéreos decayeron en un $100 \%$ en el 5 to periodo, lo cual coincide con bajos contagios. Sin embargo, estos últimos comienzan a aumentar alcanzando su punto más alto en el décimo periodo con 1.034 personas contagiadas. Misma situación se aprecia en Coquimbo.

En la Zona Centro del país se observan las tres regiones con más población del territorio nacional. Las curvas de flujos aéreos de la Metropolitana y Biobío expresan un comportamiento similar, ambas caen al tercer periodo y luego se mantienen casi constantes hasta el décimo, donde la de la Región del Biobío decae mientras que la Metropolitana se mantiene. En esta última la curva de contagios crece sin presentar caídas hasta el periodo 7 , donde registra e mayor número de contagios a nivel nacional, correspondiendo a 86.904 personas infectadas. Se debe considerar que el foco emisor de los flujos aéreos es esta región, por tanto, podría más bien ser un vector de contagios más que de recepción de ellos.

La región de Valparaíso no posee prácticamente flujos aéreos dada su cercanía con la capital del país, Santiago. Los flujos que presenta son los imputados a la isla de Rapa Nui, cuyo aeropuerto fue cerrado para evitar contagios en la isla. Por lo tanto, es una región que en términos de flujos aéreos está prácticamente descarta del análisis.

En la Zona Sur se aprecia una dispar situación. En La Araucanía, la curva de contagios aumenta a pesar que la correspondientes de los flujos disminuye considerablemente, para luego estabilizarse ambos. Caso contrario, la Región de Los Ríos, que históricamente ha presentado una baja conectividad aérea y registra una baja cantidad de contagios, siendo el territorio con uno de los mejores comportamientos a nivel país. En la Región de Los Lagos la curva de contagios alcanza su menor registro en el periodo 3, coincidente con la disminución de flujos aéreos, a pesar que estos se mantienen constante, los contagios aumentan en los periodos siguientes. La Región de Aysén es la única del país que durante dos periodos no registró contagios a pesar de una continuidad en los flujos aéreos, lo cuales es prácticamente imposible su ausencia dada la localización en la zona austral (Figura 1).

Finalmente, Magallanes presenta comportamientos similares a otras regiones. En un primer momento los vuelos disminuyen, pero se incrementan los contagios. Desde el periodo 7 u 8, existe 
un leve aumento en los flujos aéreos y la dada las condiciones geográficas y, por curva de contagios se dispara de manera tanto, la distribución de su población, en su importante, convirtiéndose en una de las capital regional Punta Arenas se concentra regiones más expuestas al virus, lo cual es aproximadamente el $80 \%$ de la población bastante relevante, considerando que, total regional.

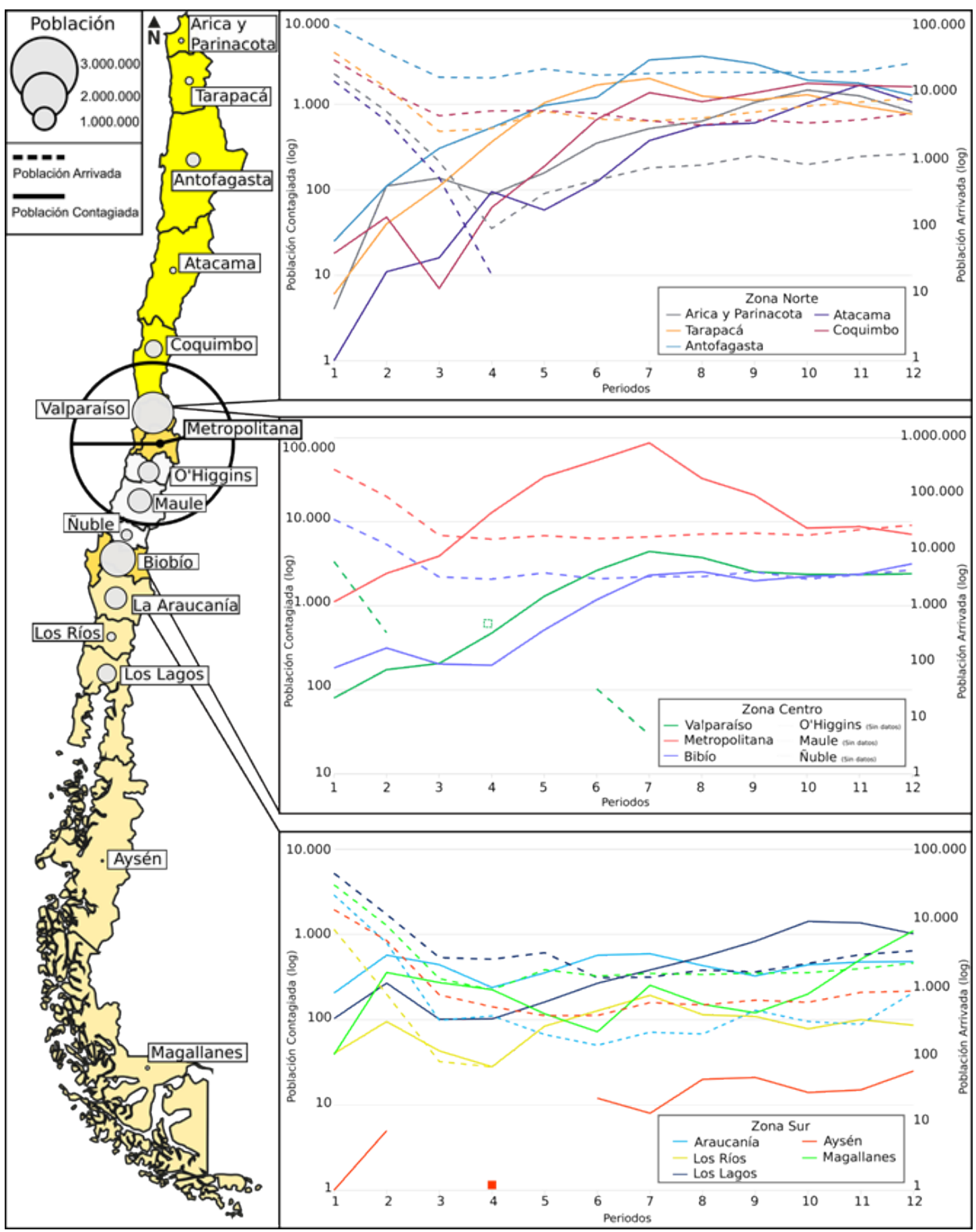

Figura 1. Contagiados y total de llegadas de pasajeros aéreos por región y periodo. Fuente: Elaboración propia a partir de MINSAL, 2020 y Junta de Aeronáutica Civil, 2020. 
La Figura 2, expresa la tasa de incidencia y la especialización en las diferentes actividades económicas de las regiones, esta última -como ya fue indicadoexpresada en un coeficiente de especialización, donde a mayor valor, se observa más concentración del empleo en una(s) rama(s) específica(s) de la actividad económica.

Las regiones del norte ostentan una alta especialización, particularmente Antofagasta y Atacama con un alto empleo de la actividad minera, superando el 15\%, lo cual es esperable considerando que Chile es el primer productor de cobre a nivel mundial. La correspondencia entre la tasa de incidencia y la especialización económica que ostentan es evidente, aunque habría que ser cautelosos y no concluir una correlación causal. En tal sentido, si se aprecia el comportamiento de la región de Antofagasta, el fenómeno indicado se cumple a cabalidad y en menor medida para Atacama, aunque de todas formas su tasa de incidencia está por sobre la gran parte de otras regiones del país (Figura 2).

Al observar otras regiones en la zona centro como Metropolitana Idonde como indicamos se concentra prácticamente la mitad de la población del país) presenta una baja especialización y una alta incidencia. Las regiones que le siguen más allá de su especialización han presentado una tasa de incidencia baja o moderada si se compara con otros territorios (Figura 2).

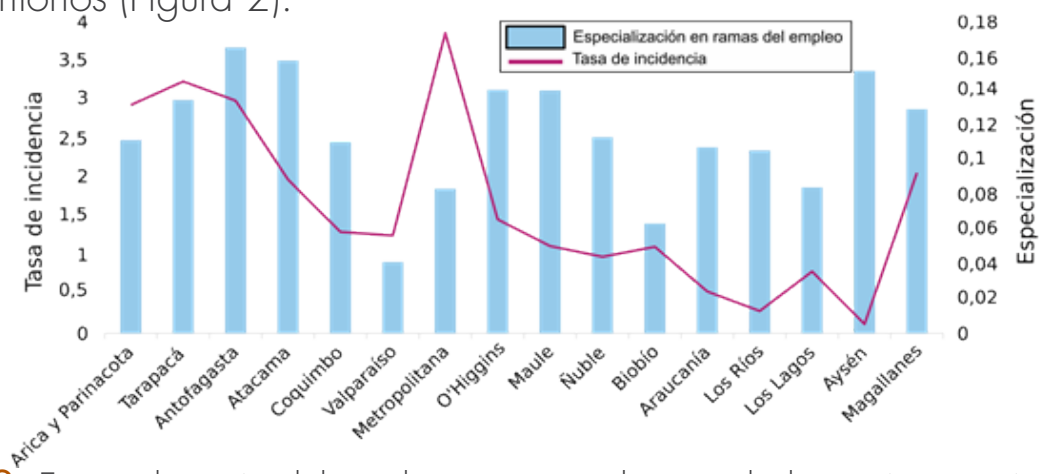

Figura 2. Especialización del empleo por rama de actividad económica e índice incidencia de contagios por región. Fuente: Elaboración propia a partir de MINSAL, 2020 e INE, 2017.
En el sur, Los Lagos, presenta una especialización en el sector pesca (Chile es el segundo productor mundial de salmón). El empleo se concentra en $14 \%$ en esta área, aunque bastante diversificada en otras áreas y, por tanto, el valor de especialización es matizado. En término de su tasa de incidencia es elevada en comparación a otros tres territorios de la zona sur y austral, aunque bastante más moderada si se compara con el norte o centro del país.

En el caso de Magallanes, su alta tasa de incidencia va también vinculada a una mayor especialización. Sin embargo, en este caso es compartida por dos ramas de actividades económicas. La primera, vinculada a empleo del sector público y, la segunda, más bien a empleos vinculados al sector pesquero, particularmente salmonicultura, actividad que ha tenido un fuerte aumento en los últimos años (lamentablemente no queda reflejada en los datos del censo 2017) y que no ha cesado del todo labores, convirtiéndose posiblemente en un importante foco propagador del virus.

Así, la figura 2, expresa la alta tasa de incidencia en las tres primeras regiones del norte del país de manera generalizada y donde los niveles de especialización y encadenamiento de la actividad minera en los diferentes territorios es evidente y si bien no podemos llegar a resultados definitorios, creemos que hay una tendencia en tal dirección. Mismo caso el ya indicado en Magallanes. 
El siguiente análisis correspondió a realizar las cinco correlaciones y regresiones lineales simples. Estas se expresan en la Figura 3, que contiene para cada correlación el valor obtenido y un p-value generado a partir de un test para observar el grado de asociación entre las variables. En el caso de cada regresión, se realiza de tipo logarítmica, dada la naturaleza de todas las variables que no presentan una distribución normal al haberles aplicado un test de Shapiro-Wilk. Para cada regresión se indica el R-squared y el p-valor del modelo generado.

En las dos primeras se observa una correlación fuerte sobre 0,9 con pruebas estadísticas de p-value significativas. El objetivo fue demostrar que existe una relación de los contagiados y muertos por Covid-19, con la cantidad de población de cada espacio regional chileno. Esto es interesante, al concluir que no se aprecia un foco emisor concentrado que esté polarizando los contagios o muertes, más allá de lo esperando en términos de población, por tanto, la Región Metropolitana, por presentar mayor población, es donde hay más casos. Es decir, en los fenómenos de difusión espacial, en los cuales se podría apreciar -entre otros- una difusión de tipo aleatoria, efecto vecino o jerárquica. En este caso pareciera que se estuviera desarrollando un tipo de propagación, más bien este último término, al considerar que la jerarquía estaría en función de la población que presenta cada territorio.

No obstante, de manera particular y más allá de la opacidad de la escala utilizada no permite observar un mayor detalle al analizar los valores residuales que emanan del modelo de regresión tanto en los contagiados como fallecidos. La Región de Antofagasta laltamente especializada en el sector minerol, presenta más contagios y defunciones de lo que estaría esperando el modelo, es decir, el comportamiento del sistema de regiones en Chile. Además, al observar la tercera gráfica se aprecia que esta región ostenta más pasajeros de lo esperado por el modelo producto de la actividad minera, situación de conmutación que ha sido constante en los últimos 30 años y relatado es varios estudios (Aroca y Atienza, 2011 ; Paredes et al., 20181. Así, destacamos lo particular de esta región, alta especialización, elevadas llegadas de pasajeros por vuelos comerciales y una alta tasa de incidencia, lo cual podríamos concluir que efectivamente la continuidad de la actividad minera puede estar influyendo en los elevados niveles de contagio en el territorio. Tal situación en general es posible de observarla para las primeras tres regiones del norte del país, más allá que en términos de flujos aéreos esta situación es algo más moderada en Arica y Parinacota y Tarapacá.

Otro caso particular, que es posible observar en las gráficas, es la ya indicada situación de Magallanes. En la Figura 1 apreciábamos el elevado volumen de contagios en los primeros meses de la pandemia, producto de la llegada de cruceros y personas contagiadas al interior de estos que elevaron los casos en tal territorio y que nuevamente vuelve a desarrollarse en esta ocasión vinculado a sectores de la salmonicultura, cuyo sector empresarial regional tuvo que implementar un sistema propio de trazabilidad y testeo (AQUA, 2020). Esto queda de manifiesto al observar las dos primeras gráficas de la Figura 3, y reforzada en la tercera de tal Figura, en la importancia en términos de flujos al comportarse sobre lo esperado según el modelo. 


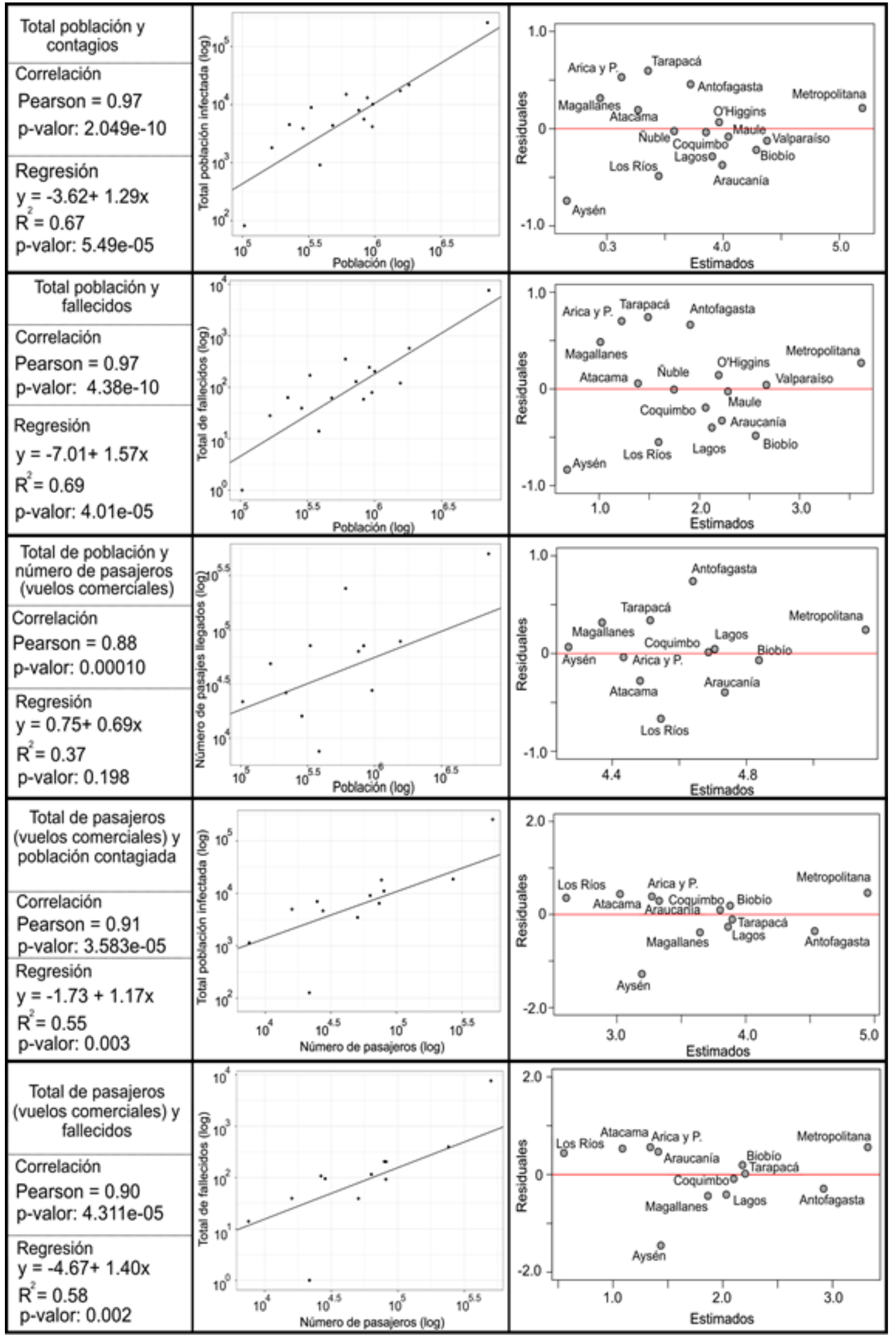

Figura 3. Correlaciones y regresiones entre población regional, contagios, fallecidos y total de llegadas. Fuente: Elaboración propia a partir de MINSAL, 2020, Junta Aeronáutica Civil, 2020 e INE, 2017. 
Sin embargo, cuando se aprecia la correlación directa entre infectados o contagiados y cantidad de pasajes por vuelos comerciales, los resultados no son del todo clarificadores. En efecto, la tercera, cuarta y quinta regresión de la gráfica 3, donde los p-valor obtenidos en el primer caso no son estadísticamente significativos y en los otros levemente menores a 0,005, dejan un sesgo abierto a la interpretación de estos.

El tercer gráfico de la Figura 3 correlaciona la cantidad de población (siempre variable independiente) con el total de pasajeros llegados por vuelos comerciales a las regiones. Más allá de su validez estadística se realiza para donar un contexto de lo observado en el cuarto y quinto proceso, en los cuales se buscó correlacionar llegadas con contagiados y llegadas con fallecidos. Respecto a tale gráficas de la Figura 3, las correlaciones de 0,9 y 0,9 con p-valores significativos son relevantes, incluso en las regresiones los r2 obtenidos bordeando los 0,6 hablan de una moderada alta de la varianza explicada, aunque con p-valor al límite del nivel de significancia. Lo cual como indicamos, si bien no necesariamente entrega una causalidad, nos podría orientar a llegar a conclusiones.

En tal sentido, existirían vínculos interesantes entre contagiados y fallecidos con las llegadas totales, sin embargo, emergen al observar los residuales algunos casos particulares, como Los Ríos, que presenta una tasa de incidencia muy baja y con pocos casos, pero emerge en este análisis con una cantidad de casos relevantes para los flujos que ostenta, mismo caso para La Araucanía o Biobío. En los casos indicados el modelo no se estaría ajustando del todo.

\section{CONCLUSIONES}

Tras el análisis realizado, se observa una alta correlación entre la cantidad de población y fallecidos, lo cual confirma el hecho que el proceso de difusión espacial de la pandemia ha seguido una estructura jerárquica del sistema regional chileno, enmarcado básicamente por la distribución de la población. Sin embargo, existen particularidades relevantes en el norte del país, donde los casos son superiores a modo general en la macrozona y se podría vincular a las actividades mineras y vuelos aéreos comerciales que pese a su disminución ostensible se continúan desarrollando, y en el último mes aumentando levemente. Tal situación sería similar a lo observable en Magallanes, donde la actividad salmonera estaría también contribuyendo a elevar los números de contagios y mismo un incremento (aunque leve) de los vuelos.

Además, si bien la escala de análisis regional podría criticarse al generar una alta opacidad en el espacio, al considerar las capitales regionales que concentran una alta población regional de sus respectivos espacios, se estima que esta le entrega un valor adicional, permitiendo visibilizar no sólo el espacio regional en sí mismo, si no que dinámicas que finalmente se desarrollan en tales comunas.

Sin embargo, resulta necesario observar los resultados con cautela, otras múltiples causas podrían estar influyendo en estos, como ausencia o presencia de cuarentenas dinámicas aplicadas, aspectos climáticos, culturales, capacidad de gestión de Gobiernos Regionales o Locales, capacidad hospitalaria y de 
personal de la salud, entre otros, que sin Barjamovic G. (2018). Interlocking duda están influyendo en las dinámicas de Commercial Networks and the Infrastructure contagio y fallecidos.

Además, si bien no se imputan directamente los flujos aéreos por motivos laborales en este trabajo, se asume en tal situación, lo cual podría ser un sesgo si tales flujos aéreos, que continuaron, corresponden a otros motivos, lo cual es imposible saber dado que no se indica tales motivos en la base de datos. No obstante, se debe considerar que la actividad minera y pesquera ha continuado sin pausas en el país, lo cual podría dar ciertos indicios.

Sin perjuicio de esto, creemos que el análisis planteado avanza el diagnóstico de un proceso diariamente cambiante y dejamos de manifiesto las preocupaciones ya señaladas. En cuanto a las regiones vinculadas a actividades extractivas se abren escenarios y preguntas para que futuros trabajos puedan ir en tal dirección, considerando que la pandemia está lejos de pasar en la actualidad y este trabajo será un punto de referencia para otras contribuciones.

\section{BIBLIOGRAFÍA}

AQUA (2020, 12 de agosto). En Magallanes: Industria del salmón se incorpora a programas de trazabilidad y testeo de Covid-19. Revista AQUA. Recuperado de https://www.aqua.cl/2020/08/12/en-m agallanes-industria-del-salmon-se-incorpora-a-pr ogramas-de-trazabilidad-y-testeo-de-covid-19/

Aroca, P., Atienza, M. (2011). Economic implications of long distance commuting in the Chilean mining industry. Resources Policy, 36(3), 196-203. hitps://doi.org/10.1016/i.resour- h pol.2011.03.004

of Trade in Western Asia during the Bronze Age. En K. Kristiansen, T. Lindkvist, \& J. Myrdal, Trade and Civilisation: Economic Networks and Cultural Ties from Prehistory to the Early Modern Era (pp 113-142). Cambridge: Cambridge University Press. https://doi.org/10.1017/9781108340 946.006

Brown, L., Cox, K. (1971). Empirical regularities in the diffusion on innovation. Annals of the Association of American Geographers, 61(3), 551-559. https://doi.org/10.2307/2569232

CDC. (2020). Geographic Differences in COVID-19 Cases, Deaths, and Incidence United States, February 12-April 7, 2020. MMWR Morb Mortal Wkly, 69(15), 465-471. htrp://dx.doi.org/10.15585/mmwr.mm691 5e4external icon.

Colizza, V., Barrat, A., Barthélemy, M., Vespignani, A. (2006). The role of the airline transportation network in the prediction and predictability of global epidemics. Proc Natl Acad Sci, 103(7), 2015-2020. http://dx.doi.org/10.1073/pnas.051052 5103

Congdon, P. (2016). Spatiotemporal Frameworks for Infectious Disease Diffusion and Epidemiology. International Journal of Environmental Research and Public Health, 13(12), 1261 htpp://doi.org/10.3390/iijerph 13121261

Cuadros, D., Xiao, Y., Mukandavire, Z., Correa-Agudelo, E., Hernández, A., Kim, H. MacKinnon, N. (2020). Spatiotemporal transmission dynamics of the COVID-19 pandemic and its impact on critical healthcare capacity. Health \& Place, 64, 102404. https://doi.org/10.1016/i.healthplace.20 20. 102404 
Ducruet, C. (2013). Mapping Global Karlen, A. (1995). Plague's Progress: A Urban Interactions: Maritime Flows and Port Social History Of Man And Disease. Hierarchies since the Late Nineteenth Centu- London: Indigo.

ry. GaWC Research Bulletin 429. Recuperado de https: //www.lboro.ac.uk/gawc/rb/rb429.html

Duplaix, N. (1988). Fleas: The lethal leapers. National. 173, 114-136.

Larsen, M. (2015). Ancient Kanesh: A Merchant Colony in Bronze Age Anatolia. Cambridge: Cambridge University Press. https://doi.org/10.1017/CBO9781316344781

Huang, R., Liu, M., Ding, Y. (2020). Spatial-temporal distribution of COVID-19 in China and its prediction: A data-driven modeling analysis. I Infect Dev Ctries, 14(3), 246-253. https://doi.org/10.3855/jidc. 12585

Instituto Nacional de Estadísticas de Chile. (2017). Bases de datos censales 2017. Recuperado de https://datosabiertos.ine.cl/dashboards/20568/censo-2017/

International Air Transport Association. (2019). World Air Transport Statistics 2019. Recuperado de hitps://mmw.iata.org/contentassets/a686ff624550453e8bfOc9b3f7fOab2 6/wats-2019-mediakit.pdf

Jia, J., Lu, X., Yuan, Y., Xu, G., Jia, J. (2020). Population flow drives spatio-temporal distribution of COVID-19 in China. Nature, 582, 389-394.

Jonassen, T., Stene-Johansen, K.E.B. (1997). Sequence analysis of the HIV-1 group $\bigcirc$ from Norwegian parents infected in the 1960s. Virology, 231, 43-47. https://doi.org/10.1006/viro. 1997.8510

Junta de Aeronáutica Civil. (2020). Estadísticas históricas. Recuperado de http://www.jac.gob.cl/estadisticas/estadisticas-historicas/
Lau, H., Khosrawipour, V., Kocbach, P., Mikolajczyk, A., Ichii, H., Zcharski, M., Bania, J., Khosrawipour, T (2020). The association between international and domestic air traffic and the coronavirus (COVID-19) outbreak. Journal of Microbiology, Immunology and Infection, 53, 467-472. https://doi.org/10.1016/i. imii. 2020.03.026.

Ministerio de Ciencia y Tecnología. (2020). Base de datos COVID-19. Recuperado de https://github.com/MinCiencia/Datos-COVID 19

Ministerio de Salud. 116 de marzo de 20201. Coronavirus en Chile pasa a fase 4 y Presidente anuncia cierre de fronteras. Recuperado de https://www.minsal.cl/coronavirus-en-chile-pasa-a-fase-4-y-presidente-anuncia-cierre-de-fr onteras/\#: :text=marzo\%20de\%202020,Coronavirus\%20en\%20Chile\%20pasa\%2 Oa\%20fase\%204\%20y\%20Presidente\%20 anuncia, contener\%20la\%20propagaci\%C 3\%B3n\%20del\%20virus.

Ministerio de Salud. (2020a). Informe de situación COVID-19. No 5. Departamento de Epidemiología. Recuperado de https://www.minsal.cl/nuevo-coronavi$r$ us - $2019-n c \circ v / i n$ forme-epidemiologico-covid-19/ 
Ministerio de Salud. (2020b). Informe de drive-in/drive-out commuters. Papers in situación COVID-19. № 8. Departamento de Regional Science, 97/4), 1337-1353. Epidemiología. Recuperado de https://ww- https://doi.org/10.1111/pirs.12296 w.minsal.cl/nuevo-coronavirus-2019-ncov/informe-epidemiologico-covid-19/

Pringle, H. (2015). How Europeans brought sickness to the New World. Science. RecuOrganización de las Naciones Unidas (ONU). (2008). International Standard Industrial Classification of All Economic Activities (ISIC) rev.4. Recuperado de https://unstats.un.org/unsd/publication/seriesM/seriesm_4rev4e.pdf

Organización Mundial de la Salud. (2020a). Naming the coronavirus disease (COVID-19) and the virus that causes it. Rogers, L. (1920). Fevers in the Tropics. Nature, Recuperado de https://www.who.in- 105(33). hitps://doi.org/10.1038/105033a0 t/emergencies/diseases/novel-coronavirus-2019/technical-guidance/naming-the-c Saccomandi, G. (1997). The spatial diffuoronavirus-disease-(covid-2019)-and-the-viru sion of diseases. Mathematical and Coms-that-causes-it

Organización Mundial de la Salud. 96-4 (2020b). COVID-19 Supply Portal: Frequently asked questions. Recuperado de Soza-Amigo, S., Mancilla, C., Ferrada, L. https: / / www. who.int/publica- (s.f.). Las especializaciones e interrelaciones tions/m/item/covid-19-supply-portal-frequently-asked-questions

Paredes, D., Soto, J., Fleming, D. (2018). Wage compensation for fly-in/fly-out and productivas como factores de desarrollo en la Patagonia chilena. Revista de geografía Norte Grande, 70, 153-181. https://dx. doi.org/10.4067/s0718-3402201800 0200153 